\title{
Kinetics and Possible Mechanisms of the Ce(IV) Oxidation of EDTA, CDTA, DTPA and NTA in Perchloric Acid Media*
}

\author{
Samir B. Hanna, William R. Carroll, Salem A. Attiga, and William H. Webb \\ Chemistry Department, University of Missouri-Rolla, Missouri, U.S.A.
}

(Z. Naturforsch. 30 b, 409-415 [1975]; received December 27, 1974)

Oxidation, Amino Acids, Kinetics, Mechanisms, Cerium(IV)

\begin{abstract}
The rates of oxidation of four chelating agents with $\mathrm{Ce}(\mathrm{IV})$ in $\mathrm{HClO}_{4}$ solutions, have been studied by the stopped-flow technique. The rates first increase with increasing acidity, reach maxima which are characteristic of the chelating agent and the medium, then progressively decrease with further increasing acid concentration. At their maximum reactivities, the tendencies for oxidation decrease in the following order: trans-1,2-diaminocyclohexane tetraacetic acid (CDTA) $>$ ethylenedinitrilotetraacetic acid (EDTA) $>$ diethylenetriaminepentaacetic acid (DTPA) $>$ nitrilotriacetic acid (NTA). A mechanism for the oxidation of EDTA, involving $\mathrm{Ce}^{4+}$ and $\mathrm{Ce}(\mathrm{OH})^{3+}$ and both unprotonated and monoprotonated chelating agent, is proposed.
\end{abstract}

The complexation of polyaminocarboxylic acids commonly used as chelating agents and recently as possible substitutes for phosphates in detergents with trivalent lanthanides has been extensively investigated ${ }^{1-3}$. On the other hand, the reactions of these polyaminocarboxylic acids with $\mathrm{Ce}(\mathrm{IV})$ have received little attention, apparently because oxidation rather than complexation is the observed reaction in such systems ${ }^{4}$.

The rates of oxidation of several chelating agents by alkaline ferricyanide $\left[\mathrm{Fe}(\mathrm{CN})_{6}\right]^{3-}$ were studied by LAMBERT and JONES ${ }^{5}$ who found that four moles of ferricyanide were consumed per mole of EDTA; the products then were reported to be iminodiacetic acid and glycollic acid. Recently, Mushran et al. found that seven moles of chloramine-T were consumed per mole oxidation of EDTA ${ }^{6}$.

Our previous investigations on the $\mathrm{Ce}(\mathrm{IV})$ oxidation of EDTA, CDTA, DTPA, and NTA were carried out in aqueous $\mathrm{H}_{2} \mathrm{SO}_{4}{ }^{7-10}$, where $\mathrm{Ce}(\mathrm{IV})$ forms strong sulfato complexes ${ }^{11}$. Such complexation only adds to the difficulties of formulating

* This is part VII of a series on oxidative decarboxylation with $\mathrm{Ce}(\mathrm{IV})$. For part VI, see reference 10 .

Requests for reprints should be sent to Prof. Dr. S. B. Hanna, College of Arts and Sciences, Department of Chemistry, 142 Chemistry Bldg., Rolla, Missouri 65401, USA. possible reaction mechanisms. In aqueous $\mathrm{HClO}_{4}$, on the other hand, $\mathrm{Ce}(\mathrm{IV})$ exists mainly as the hydrolyzed species $\mathrm{Ce}(\mathrm{OH})^{3+}$ and $\mathrm{Ce}(\mathrm{OH})_{2}{ }^{2+}$ along with the dimer $(\mathrm{Ce}-\mathrm{O}-\mathrm{Ce})^{6+12-15}$. At high acidities, the non-hydrolyzed $\mathrm{Ce}^{4+}$ exists as a major fraction of the stoichiometric concentration of $\mathrm{Ce}(\mathrm{IV})$. Such a species is expected to be far more reactive than complexed $\mathrm{Ce}(\mathrm{IV})$ and would accordingly be a very efficient oxidizing agent. This paper deals with a study of the $\mathrm{Ce}(\mathrm{IV})$ oxidation of EDTA, CDTA, DTPA, and NTA in $\mathrm{HClO}_{4}$ solutions.

\section{Experimental}

\section{Reagents}

Ceric perchlorate (perchlorato ceric acid), $\mathrm{H}_{2} \mathrm{Ce}\left(\mathrm{ClO}_{4}\right)_{6}$, stock solution $\left(0.5 \mathrm{M}\right.$ in $\left.6 \mathrm{M} \mathrm{HClO}_{4}\right)$ was purchased from G. Frederick Smith Chemical Co., Columbus, Ohio. Perchloric acid dolutions were made by dilution from $70 \%$ Fisher reagent which meets A.C.S. specifications. Monohydrated sodium perchlorate, and anhydrous sodium sulfate were analytical reagent grades. The primary standard was reagent-grade ferrous ammonium sulfate (Mohr's salt) $\mathrm{FeSO}_{4} \cdot\left(\mathrm{NH}_{4}\right)_{2} \mathrm{SO}_{4} \cdot 6 \mathrm{H}_{2} \mathrm{O}$;o-phenanthroline was used as indicator.

The base indicator for Hammett acidity function determinations was $o$-nitroaniline $(\mathrm{pKa}=-0.29)$. It was used after recrystallization from benzene.

The solutions of the chelating agents NTA, EDTA, CDTA, and DTPA (Merck, Eastman Kodak, and Geigy) were prepared by direct weighing. Except for EDTA, which is water soluble as the disodium 
salt, dilute $(0.1 \mathrm{~N}) \mathrm{NaOH}$ solution was used for the other not readily soluble polyaminocarboxylic acids.

\section{Stoichiometry}

The stoichiometry of the reaction between $\mathrm{Ce}(\mathrm{IV})$ and EDTA in $\mathrm{HClO}_{4}$ media was determined by allowing a known excess of a standardized solution $(0.079 \mathrm{M})$ of $\mathrm{Ce}(\mathrm{IV})$ in $\mathrm{HClO}_{4}$ to react with $1-\mathrm{ml}$ samples of $0.1 \mathrm{M}$ EDTA solution for a period of time ranging from a few seconds to several hours at room temperature. At recorded periods of time, the $\mathrm{Ce}(\mathrm{IV})$ consumed was determined by titrating the mixture against standard $\mathrm{Fe}(\mathrm{II})$ solution. When the reaction time was less than 30 minutes, the reaction was quenched by addition of a known volume of $\mathrm{Fe}(\mathrm{II})$ which was stored in the side arm of the reaction flask and by back titration against $\mathrm{Cr}(\mathrm{VI})$.

\section{Rate measurements}

The rates of reduction of $\mathrm{Ce}(\mathrm{IV})$ with EDTA, CDTA, DTPA and NTA, respectively, were studied spectrophotometrically at $\sim 300 \mathrm{~nm}$ where $\mathrm{Ce}(\mathrm{IV})$ in $\mathrm{HClO}_{4}$ absorbs strongly; neither $\mathrm{Ce}(\mathrm{III})$, nor the chelating agents or their reaction products interfere at this wavelength. The reactions were too fast to study by the ordinary techniques, and use was made of the commercially available Durrum-Gibson stopped-flow apparatus which allows measurements of half-lives in the millisecond region. Constant temperatures were maintained $\pm 0.05^{\circ} \mathrm{C}$ by a circulating Lauda Ultrathermostat in combination with a cooling system. The solutions of $\mathrm{Ce}(\mathrm{IV})$ in $\mathrm{HClO}_{4}$ and of the chelating agents of known molarities were injected by a pressure shock into a mixing chamber where mixing is complete within two milliseconds. The change in the percent transmittance with time, at the chosen wavelength, was displayed on the screen of an attached Tektronix storage oscilloscope. A permanent record of the display was photographed on a Polaroid film. A typical percent transmittance $v s$ time sweep is shown in Fig. 1.

The concentrations of the chelating agents (Chel) and of $\mathrm{Ce}(\mathrm{IV})$ in the mixed reaction solutions were usually about $2.50 \times 10^{-2} \mathrm{M}$ and $3.50 \times 10^{-4} \mathrm{M}$ respectively, i.e., $[\mathrm{Chel}]_{0}:[\mathrm{Ce}(\mathrm{IV})]_{0}$ was about $70: 1$.

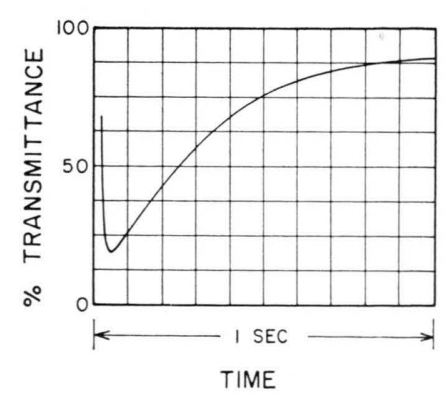

Fig. 1. Stopped-flow of three superimposed oscilloscope traces of $\mathrm{Ce}(\mathrm{IV})$-NTA reaction.
The great excess of [Chel $]_{0}$ insured simple first-order variation in $[\mathrm{Ce}(\mathrm{IV})]$. The half-life of $[\mathrm{Ce}(\mathrm{IV})]_{0}$ was read directly from the oscilloscope screen. It was the time when the absorbance had reached half its initial value if the final reading was $100 \%$ transmittance, or at half the total change in absorbance when after 20 half-lives the transmittance was not $100 \%$. The half-lives so obtained were translated to first-order rate constants; thus,

$$
k_{1}=0.693 / \tau_{0.5} \sec ^{-1}
$$

Second-order rate constants, $k_{2}$, were calculated from the corresponding $k_{1}$ by dividing the latter by the initial concentration of the chelating agent $[\mathrm{Chel}]_{0}$; thus,

$$
k_{2}=k_{1} /[\mathrm{Chel}]_{0} \mathrm{M}^{-1} \mathrm{sec}^{-1} \text {. }
$$

\section{Results and Discussion}

\section{a. Stoichiometry of the EDTA-Ce(IV) reaction}

The reaction between $\mathrm{Ce}(\mathrm{IV})$ and EDTA in aqueous $1 \mathrm{M} \mathrm{HClO}_{4}$ exhibits variable stoichiometry. In Table I evidence for the dependence of the

Table I. Stoichiometry of EDTA-Ce(IV) reaction as a function of time.

\begin{tabular}{cl}
\hline $\begin{array}{l}\text { Time } \\
\text { [min.] }\end{array}$ & $\begin{array}{l}\text { Number of equivalents of Ce(IV) } \\
\text { consumed per mole of EDTA }\end{array}$ \\
\hline $0^{*}$ & $4.10,4.20,4.30$ \\
0.3 & 5.90 \\
1.0 & 6.60 \\
5.0 & 7.30 \\
10.0 & 7.80 \\
30.0 & 8.90 \\
140.0 & 11.80 \\
630.0 & 13.70 \\
\hline
\end{tabular}

* This was done by mixing the two reagents by injection and immediate quenching by Fe(II) which was stored in the side arm of the reaction flask.

stoichiometry on time is presented. An average of 4.2 moles of $\mathrm{Ce}(\mathrm{IV})$, recorded for three separate runs, represents the lowest amount of $\mathrm{Ce}(\mathrm{IV})$ found to react, almost instantaneously, per mole of EDTA. Ultimate consumption of about 14 equivalents of $\mathrm{Ce}(\mathrm{IV})$ per mole of EDTA was observed. In $\mathrm{H}_{2} \mathrm{SO}_{4}$ medium the stoichiometry ranged from a low of about 4 to a high of about $14^{7}$. In addition to $\mathrm{CO}_{2}$ and formaldehyde ${ }^{7}$, various organic products have been detected by paper electrophoresis ${ }^{16}$. A summary of the possible $\mathrm{Ce}(\mathrm{IV})$ interactions in the system appears in Chart 1. 


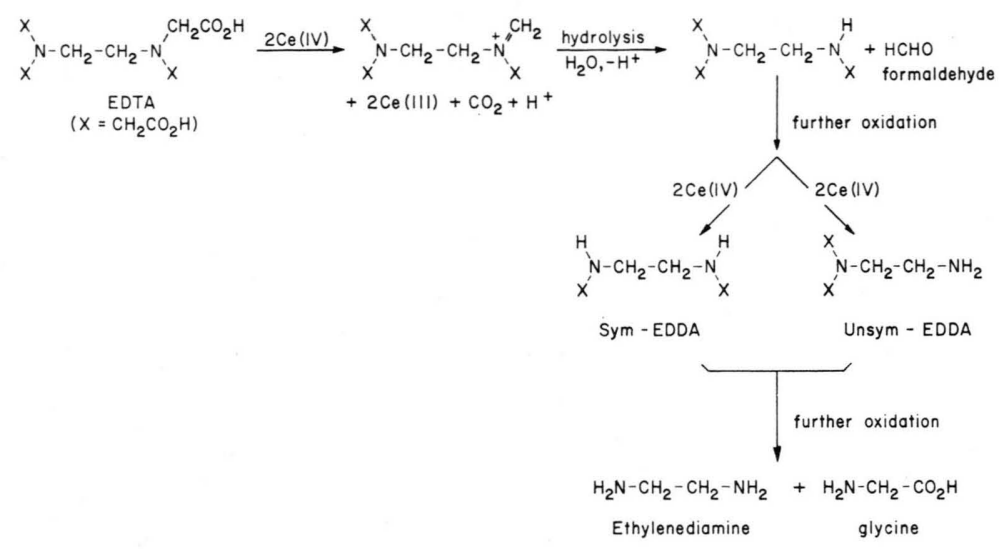

Following the first decarboxylation, several paths for further oxidation are available. These consecutive and concurrent reactions are expected to yield the observed time-dependent stoichiometry. Furthermore, the hydrolysis of the charged Schiff's base (Chart 1) yields formaldehyde which is oxidized by $\mathrm{Ce}(\mathrm{IV})$ readily ${ }^{17}$, and therefore is expected to contribute to the observed high consumption of the oxidant. However, because of the large difference in reaction rates, the formed formaldehyde does not interfere strongly with either the stoichiometry or the rate of $\mathrm{Ce}(\mathrm{IV})$ consumption at the early stages of the studied reactions.

\section{b. Acidity dependence}

The second-order rate constants for the oxidation of the four polyaminocarboxylic acids in $\mathrm{HClO}_{4}$ media are shown collectively in Fig. 2. For each acid a maximum in the plot of $\log k_{2} v s\left[\mathrm{HClO}_{4}\right]$ is observed. When the acidity of the medium was varied but the ionic strength kept constant at $\mu=5.0$, a similar parabola for $\log k_{2}$ vs $\left[\mathrm{HClO}_{4}\right]$ was obtained in the EDTA case. A similar bell-shape behavior was observed in $\mathrm{H}_{2} \mathrm{SO}_{4}$ media ${ }^{7,8}$. However, it is hardly likely that one and the same explanation can be advanced for both media. In $\mathrm{H}_{2} \mathrm{SO}_{4}$, the $\mathrm{Ce}(\mathrm{IV})$ becomes heavily complexed, and therefore deactivated, as the $\mathrm{SO}_{4}{ }^{2-}$ and $\mathrm{HSO}_{4}{ }^{-}$concentrations increase accompanying increases in $\left[\mathrm{H}_{2} \mathrm{SO}_{4}\right]$. With $\mathrm{ClO}_{4}^{-}$, where complexation is minimal ${ }^{18}$, the rates decrease rapidly with increasing $\left[\mathrm{HClO}_{4}\right]$ just the same as with increasing $\left[\mathrm{H}_{2} \mathrm{SO}_{4}\right]$. To the left of the maxima, the increase in rate with increasing acidity may be explained generally in terms of a model which portrays the $\mathrm{Ce}(\mathrm{IV})$ coordinated by both $\mathrm{N}$ and carboxylate ligands. The quality of $\mathrm{Ce}(\mathrm{IV})$ as an electron sink is not fully sensed by the carboxylate as long as the electron pair of the $\mathrm{N}$ ligand occupies one of the positions available around the metal ion. With increasing acidity, $\mathrm{H}^{+}$competes with $\mathrm{Ce}(\mathrm{IV})$ as an electron pair acceptor and when $\mathrm{N}$ is protonated, the $\mathrm{Ce}(\mathrm{IV})$ character as an electron sink is enhanced and electron transfer from a coordinated carboxylate takes place.

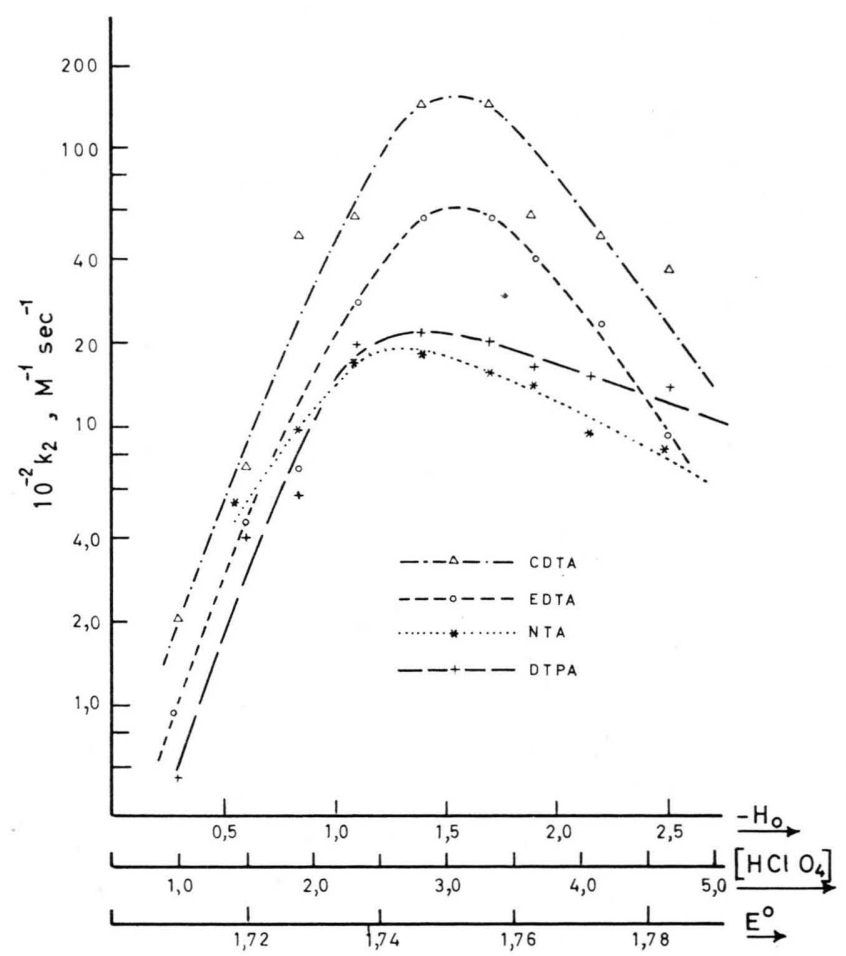

Fig. 2. Reaction rate constants as a function of Hammett acidity, stoichiometric concentration of $\mathrm{HClO}_{4}$ and formal oxidation potential of $\mathrm{Ce}$ (IV)/Ce(III) couple. 


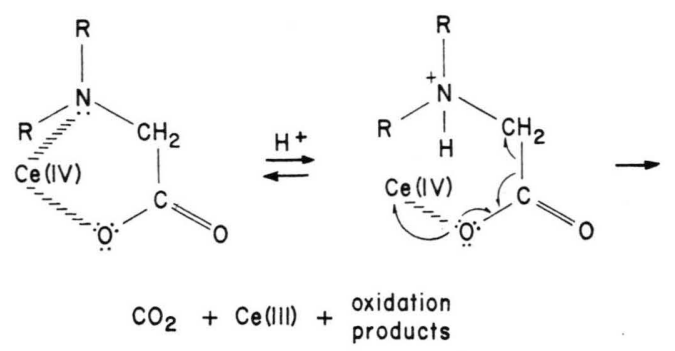

To the right of the maxima, extensive protonation of the aminoacid (and progressive sulfato complexation of $\mathrm{Ce}(\mathrm{IV})$ in $\mathrm{H}_{2} \mathrm{SO}_{4}$ solution) with increasing acidity is probably the main reason behind the observed decreased reactivity. Fully protonated polyaminocarboxylic acids, e. g., $\mathrm{H}_{2} \mathrm{EDTA}^{2+}\left(\mathrm{H}_{6} \mathrm{Y}^{2+}\right)$, cannot conceivably coordinate with $\mathrm{Ce}(\mathrm{IV})$, and if complexation is a prerequisite for electron transfer ${ }^{19}$, the decreased reactivity with increasing acidity is to be expected. We will develop a quantitative description for the bell-shape behavior later in the paper under Mechanism.

\section{c. Relative reactivities}

At the respective maxima, the reactivities of the four polyaminocarboxylic acids as reducing agents towards $\mathrm{Ce}(\mathrm{IV})$ in aqueous $\mathrm{HClO}_{4}$ decreases in the order CDTA $>$ EDTA $>$ DTPA $>$ NTA. At a fixed acidity, the oxidation of these chelating agents by $\mathrm{Ce}(\mathrm{IV})$ follows an overall second-order rate equation, first order in each of the reagents. Thus,

$$
-\frac{\mathrm{d}[\mathrm{Ce}(\mathrm{IV})]}{\mathrm{dt}}=k_{2}[\mathrm{Ce}(\mathrm{IV})][\mathrm{Chel}] \text {. }
$$

The highest values for $k_{2}$, in $\mathrm{M}^{-1} \mathrm{sec}^{-1}$ at $25^{\circ} \mathrm{C}$, are $138 \times 10^{2}$ for CDTA at about $3-3.5 \mathrm{M} \mathrm{HClO}_{4}$; $55 \times 10^{2}$ for EDTA at about $3-3.5 \mathrm{M} \mathrm{HClO}_{4}$; $22 \times 10^{2}$ for DTPA at about $3 \mathrm{M}^{\mathrm{HClO}_{4}}$; and $17 \times 10^{2}$ for NTA at about $2.5-3 \mathrm{M} \mathrm{HClO}_{4}$.

The difference in reactivities of EDTA and CDTA may be explained in terms of their geometries and hexadentate coordinating abilities, ${ }^{8,20}$. DTPA, on the other hand, has enough centers for octadentate coordination which has been suggested for some tetravalent metal ions, e.g., $\mathrm{Th}(\mathrm{IV})^{21}$, and $\mathrm{Ce}(\mathrm{IV})^{22}$. This is reflected in the fact that DTPA-M(IV) complexes are thermodynamically more stable than the EDTA analogues ${ }^{21}$. This, however, should not be taken to imply that DTPA complexes are formed faster. Actually, among the three chelating agents, EDTA, CDTA and DTPA, only the latter has a rate of complexation with $\mathrm{Ce}(\mathrm{IV})$ slow enough to be measurable ${ }^{9,10}$. This is probably a reflection of the need for octadentate coordination attainable through conformational adjustments and unfavorable entropy change.

In the NTA case neither hexadentate nor octadentate coordination can be achieved through $1: 1$ interaction with $\mathrm{Ce}(\mathrm{IV})$. Recently, MaLININA et al. ${ }^{23}$, provided evidence for a $1: 1$ complex in sulfate media where $\mathrm{Ce}(\mathrm{IV})$ is strongly sulfato-complexed, and a 2 NTA: $1 \mathrm{Ce}(\mathrm{IV})$ complex in nitrate media where the $\mathrm{Ce}(\mathrm{IV})$ is not as strongly nitrato-complexed. Extrapolation to our perchlorate media, where perchlorato-complexation is minimal if not totally absent, would suggest the need for 2 NTA molecules for coordination prior to electron transfer; this would account - through entropy considerations - for a slower reaction rate with NTA. However, this suggestion is not supported kinetically.

It is interesting to note that while CDTA is almost 400 times more reactive than NTA in $\mathrm{H}_{2} \mathrm{SO}_{4}{ }^{8}$, it is only 7 times as reactive as NTA in $\mathrm{HClO}_{4}$ at their points of maximum reactivities. This leveling effect in $\mathrm{HClO}_{4}$ is true for the other chelating agents too, and may be explained in terms of the higher selectivity of a sulfato-complexed $\mathrm{Ce}(\mathrm{IV})$ vs the higher reactivity of a non-complexed $\mathrm{Ce}(\mathrm{IV})$ in $\mathrm{HClO}_{4}$ solutions.

\section{d. Salt effects and effect of ionic strength}

Although the ionic strengths, $\mu$, in the reaction media were too high to draw any quantitative conclusions from the application of the BrönstedBjerrum equation, we studied the effect of added salts in the hope of gaining some knowledge pertaining to the charges of the reacting species. With addition of $\mathrm{NaClO}_{4}$ at an initial fixed $\left[\mathrm{HClO}_{4}\right], k_{2}$ increases steadily with $\mu$ (Table II). This increase cannot, however, be solely attributed to a primary kinetic salt effect. Previous investigators have shown that neutral salts have a marked effect on the protonating power of the medium as measured by the Hammett acidity function, $\mathrm{H}_{0}{ }^{24}$. In this work, we found that $\mathrm{Na}_{2} \mathrm{SO}_{4}$ and $\mathrm{NaClO}_{4}$ have opposite effects on $\mathrm{H}_{0}$ when added to $\mathrm{HClO}_{4}$ solutions where the original $\mathrm{H}_{0}$ was -0.25 (Table III). The effect of $\mathrm{Na}_{2} \mathrm{SO}_{4}$ may result from binding the protons of the medium to form the acid $\mathrm{HSO}_{4}^{-}$, weaker than $\mathrm{HClO}_{4}$. With addition of $\mathrm{NaClO}_{4}$, however, a decisive increase in $-\mathrm{H}_{0}$ is noted. This can be 
Table II. Salt effects on EDTA-Ce(IV) reaction in $\mathrm{HClO}_{4}-\mathrm{NaClO}_{4}$ solutions at $25^{\circ} \mathrm{C}$.

\begin{tabular}{llllll}
\hline $\begin{array}{l}\text { Ionic strength } \\
{[\mu]}\end{array}$ & $\begin{array}{l}\tau_{1 / 2} \\
{[\mathrm{msec}]}\end{array}$ & $k_{2}{ }^{\mathrm{a}}$ & $\begin{array}{c}k_{2}{ }^{\mathrm{b}} \\
{\left[\mathrm{M}^{-1}\right.}\end{array}$ & $\begin{array}{r}\Delta k_{2}{ }^{\mathrm{c}} \\
\left.\mathrm{sec}^{-1}\right]\end{array}$ & $k_{2}{ }^{\mathrm{d}}$ \\
\hline 1.2 & 230 & 120 & 103 & 22 & 98 \\
1.4 & 200 & 138 & 125 & 44 & 94 \\
1.6 & 180 & 154 & 148 & 67 & 87 \\
1.8 & 160 & 170 & 170 & 89 & 81 \\
2.0 & 130 & 210 & 210 & 129 & 81 \\
2.5 & 95 & 290 & 290 & 210 & 80 \\
\hline
\end{tabular}

$[\text { EDTA }]_{0}=2.5 \times 10^{-2} \mathrm{M} ;[\mathrm{Ce}(\mathrm{IV})]_{0}=3.5 \times 10^{-4} \mathrm{M}$. Hammett acidity function, $-\mathrm{H}_{0}$, before salt additions $=0.25$.

a Observed second-order rate constants.

b Second-order rate constants calculated for the increase in $-\mathrm{H}_{0}$ accompanying salt additions.

c The difference between (b) and $k_{2}$ at $-\mathrm{H}_{0}=0.25$ (without added salt); this difference is due to the change of $\mathrm{H}_{0}$. The value of $k_{2}$ at $-\mathrm{H}_{0}=0.25$ is $81 \mathrm{M}^{-1} \mathrm{sec}^{-1}$.

d Second-order rate constant corrected for change in $\mathrm{H}_{0}$ and reflecting only changes in ionic strength due to salt addition.

Table III. Salt effects on Hammett acidity function. Original $-\mathrm{H}_{0}=0.25$.

\begin{tabular}{lrlll}
\hline$\left[\mathrm{Na}_{2} \mathrm{SO}_{4}\right]$ & $-\mathrm{H}_{0}$ & & {$\left[\mathrm{NaClO}_{4}\right]$} & $-\mathrm{H}_{0}$ \\
\cline { 5 - 5 } \cline { 4 - 5 } 0.2 & 0.18 & & 0.2 & 0.29 \\
0.4 & 0.11 & & 0.4 & 0.35 \\
0.6 & 0.08 & & 0.6 & 0.39 \\
0.8 & -0.01 & & 0.8 & 0.45 \\
1.0 & -0.07 & & 1.0 & 0.48 \\
1.2 & -0.09 & & 1.5 & 0.56 \\
& & & 2.0 & 0.68 \\
\hline
\end{tabular}

attributed to the decrease in water activity in the medium due to the solvation of the added salt.

Analysis of the results summarized in Table II suggests that the observed rate constants may be expressed in the form,

$$
k_{\text {observed }}=k_{\mathrm{o}}+\Delta k_{\delta \mathrm{H}_{\mathrm{o}}}+\Delta k_{\mathrm{salt}}
$$

where $k_{0}$ denotes the rate constant at the initial acidity before salt addition, $\Delta k_{\delta \mathrm{H}_{\mathrm{o}}}$ denotes the increment in the rate constant due to the change of acidity $\left(-\mathrm{H}_{0}\right)$ caused by salt addition, and $\Delta k_{\text {salt }}$ denotes the part of the rate constant due to salt effect apart from the effect due to changing $\mathrm{H}_{0}$.

By referring to Table III we computed the change in $\mathrm{H}_{0}$ due to addition of $\mathrm{NaClO}_{4}$. From the dependence of $k_{2}$ on $\mathrm{H}_{0}$ (Fig. 2) we calculated the value of $k_{2}$ expected for the increase accompanying salt addition. When the observed rate constants are corrected for the change in $\mathrm{H}_{0}$, one finds that there is no appreciable effect for increasing the ionic strength (Column $d$ in Table II). This result may be taken to imply that one of the reactants has zero charge. Since $\mathrm{Ce}(\mathrm{IV})$ cannot exist as an uncharged species in $\mathrm{HClO}_{4}$ solution, the results suggest that the reaction probably involves the unprotonated polyaminocarboxylic acid, $\mathrm{H}_{4} \mathrm{Y}$.

In confirmation of the proposal that the effect of added $\mathrm{NaClO}_{4}$ merely enhances the acidity of the medium is the fact that on addition of $\mathrm{NaClO}_{4}$ to the $\mathrm{Ce}(\mathrm{IV})-\mathrm{EDT} A$ reaction mixture, $k_{2}$ decreased if the initial acidity of the medium was beyond its value at the inflection point, and increased if the acidity was originally below $3 \mathrm{M} \mathrm{HClO}_{4}$.

\section{e. Activation parameters}

The oxidation of EDTA by $\mathrm{Ce}(\mathrm{IV})$ in $2.2 \mathrm{M} \mathrm{HClO}_{4}$ was studied in the temperature range of $15-35{ }^{\circ} \mathrm{C}$. The entropies of activation, $\Delta \mathrm{S}^{*}$, are large and negative $\left(-30.6\right.$ e.u. at $15{ }^{\circ} \mathrm{C}$ and -27.8 e.u. at $35^{\circ} \mathrm{C}$ ). This may be indicative of the occurrence of a free-radical process ${ }^{25}$, and may also be a reflection of the conformational adjustments which the EDTA molecule must undergo to coordinate with $\mathrm{Ce}(\mathrm{IV})$ prior to electron transfer. In dilute $\mathrm{HClO}_{4}$ solutions, the formation of an unstable Ce(IV)-EDTA complex has been reported ${ }^{26}$. We have also observed complex formation even in $\mathrm{H}_{2} \mathrm{SO}_{4}$ solution $(\mathrm{pH}=2)^{7}$.

\section{f. Mechanism}

The rate $v s$ acidity reaction profiles observed in this work may be explained in terms of mechanistic pathways involving certain active species whose concentrations are controlled by the acidity of the medium in such a way as to produce the bell-shaped dependence of $k_{2}$ on $\left[\mathrm{H}^{+}\right]$. We propose a rate equation (at constant $[\mathrm{Ce}(\mathrm{IV})]$ and $[\mathrm{Chel}])$ of the form

$$
\text { Rate }=k_{2}{ }^{\prime} \alpha_{\mathrm{Ce}} \cdot \alpha_{\text {Chel }}
$$

where $\alpha_{\mathrm{Ce}}$ and $\alpha_{\text {Chel }}$ represent the fractions of the stoichiometric concentrations of both reactants participating in the formation of the activated complex. The main species in $\mathrm{HClO}_{4}$ are the unhydrolyzed $\mathrm{Ce}\left(\mathrm{H}_{2} \mathrm{O}\right)_{n}{ }^{4+}$, the hydrolyzed $\mathrm{CeOH}\left(\mathrm{H}_{2} \mathrm{O}\right)_{n-1}{ }^{3+}$, and $\mathrm{Ce}(\mathrm{OH})_{2}\left(\mathrm{H}_{2} \mathrm{O}\right)_{n-2}{ }^{2+12-15}$. Although evidence for dimeric species, e.g., $(\mathrm{Ce}-\mathrm{O}-\mathrm{Ce})^{4+},(\mathrm{HOCe}-\mathrm{O}-\mathrm{CeOH})^{6+}$, etc. has been given $^{27}$, their importance can be ignored in solutions which are $<10^{-3} \mathrm{M} \mathrm{Ce}(\mathrm{IV})$. The concentrations of 
the various species of $\mathrm{Ce}(\mathrm{IV})$ which may exist in $\mathrm{HClO}_{4}$ are governed by the following equilibria:

$$
\begin{aligned}
\mathrm{Ce}^{4+}+\mathrm{H}_{2} \mathrm{O} & \stackrel{\mathrm{K}_{1}}{\rightleftarrows} \mathrm{Ce}(\mathrm{OH})^{3+}+\mathrm{H}^{+} \\
& \mathrm{K}_{2} \\
\mathrm{Ce}(\mathrm{OH})^{3+}+\mathrm{H}_{2} \mathrm{O} & \rightleftarrows \mathrm{Ce}(\mathrm{OH})_{2}{ }^{2+}+\mathrm{H}^{+}
\end{aligned}
$$

The latest values for $\mathrm{K}_{1}$ and $\mathrm{K}_{2}$ are 6.4 and 0.12 respectively ${ }^{12}$. In calculating the fraction of $\mathrm{Ce}(\mathrm{IV})$ which exists as the unhydrolyzed species at a particular $\left[\mathrm{H}^{+}\right]$, use is made of the above equilibrium constants. Thus,

$$
\frac{1}{\alpha_{\mathrm{Ce}}}=1+\frac{\mathrm{K}_{1}}{\left[\mathrm{H}^{+}\right]}+\frac{\mathrm{K}_{1} \mathrm{~K}_{2}}{\left[\mathrm{H}^{+}\right]^{2}}
$$

where $\alpha_{\mathrm{Ce}}$ refers to the unhydrolyzed $\mathrm{Ce}^{4+}$ species. Computations according to equation (4) indicate that $\alpha_{\mathrm{Ce}}$ increases with acidity in $\mathrm{HClO}_{4}$ solutions (Table IV). This unhydrolyzed species is probably

Table IV. Concentration distribution of $\mathrm{Ce}(\mathrm{IV})$ and EDTA species at different acidities.

\begin{tabular}{lllll}
\hline$\left[\mathrm{H}^{+}\right]$ & $\alpha \mathrm{Ce}^{4+}$ & $\alpha \mathrm{Ce}(\mathrm{OH})^{3+}$ & $\alpha_{\mathrm{H}_{4} \mathrm{Y}}$ & $\alpha_{\mathrm{H}_{5} \mathrm{Y}^{+}}$ \\
\hline 0.1 & 0.007 & 0.451 & 0.270 & 0.675 \\
0.2 & 0.019 & 0.610 & 0.147 & 0.735 \\
0.3 & 0.032 & 0.690 & 0.097 & 0.728 \\
0.4 & 0.045 & 0.731 & 0.070 & 0.704 \\
0.5 & 0.059 & 0.758 & 0.054 & 0.675 \\
0.6 & 0.072 & 0.773 & 0.043 & 0.646 \\
1.0 & 0.122 & 0.782 & 0.021 & 0.543 \\
2.0 & 0.227 & 0.720 & 0.007 & 0.831 \\
3.0 & 0.310 & 0.661 & 0.004 & 0.292 \\
4.0 & 0.377 & 0.600 & 0.002 & 0.237 \\
5.0 & 0.432 & 0.548 & 0.001 & 0.199 \\
\hline
\end{tabular}

the most active $\mathrm{Ce}(\mathrm{IV})$ species in the reaction medium, and an increase in its concentration would lead to an increase in the observed rate according to equation (1).

Equation (5) was used to calculate the fraction of EDTA, $\alpha_{\mathrm{H}_{4} \mathrm{Y}}$, which exists as the non-protonated species at a particular $\left[\mathrm{H}^{+}\right]$,

$$
\frac{1}{\alpha_{\mathrm{H}_{4} \mathrm{Y}}}=1+\mathrm{K}_{5}\left[\mathrm{H}^{+}\right]+\mathrm{K}_{5} \mathrm{~K}_{6}\left[\mathrm{H}^{+}\right]^{2}
$$

where $K_{5}$ and $K_{6}$ denote the equilibria

$$
\begin{aligned}
& \stackrel{\mathrm{K}_{5}}{\mathrm{H}_{4} \mathrm{Y}+\mathrm{H}^{+}} \underset{\mathrm{H}_{5} \mathrm{Y}^{+}}{\rightleftarrows} \\
& \mathrm{K}_{6} \\
\mathrm{H}_{5} \mathrm{Y}^{+}+\mathrm{H}^{+} & \rightleftarrows \mathrm{H}_{6} \mathrm{Y}^{2+}
\end{aligned}
$$

With values of $K_{5}$ and $K_{6}$ of 25 and 0.8 respectively ${ }^{28}$, one can see that $\alpha_{\mathrm{H}_{4} \mathrm{Y}}$ decreases from 0.27 at $0.1 \mathrm{M} \mathrm{H}^{+}$to 0.021 at $1 \mathrm{M} \mathrm{H}^{+}$and to 0.004 at $3 \mathrm{M} \mathrm{H}^{+}$. In other words, the concentration of the unprotonated species, $\mathrm{H}_{4} \mathrm{Y}$, decreases drastically with increasing acidity (Table IV).

In strongly acidic media, there are practically no anions of polyaminocarboxylic acids. Among the other possible species, the unprotonated form is the most amenable to loss of electrons and, therefore, to oxidation. If equation (1) represents the reaction between $\mathrm{Ce}^{4+}$ and $\mathrm{H}_{4} \mathrm{Y}$, the product $\alpha_{\mathrm{Ce}} \cdot \alpha_{\mathrm{Chel}}$ is observed to increase with increasing $\left[\mathrm{H}^{+}\right]$to a maximum at $\sim 0.4 \mathrm{M} \mathrm{H}^{+}$and then declines rapidly (Fig. 3). A better fit with experiment is given by the dotted parabola in Fig. 3 which portrays a reaction path involving $\mathrm{Ce}^{4+}$ and $\mathrm{H}_{5} \mathrm{Y}^{+}$. Using equation (1), one obtains a maximum rate for $\alpha_{\mathrm{Ce}^{4}} \cdot \cdot \alpha_{\mathrm{H}_{5} \mathrm{Y}}+$ at $3.2 \mathrm{M} \mathrm{H}^{+}$; the experimental maximum for the $\mathrm{Ce}(\mathrm{IV})-\mathrm{EDTA}$ reaction is at $3-3.5 \mathrm{M} \mathrm{HClO}_{4}$. So, although salt effect studies suggest a reaction with $\mathrm{H}_{4} \mathrm{Y}$, a reaction path involving $\mathrm{H}_{5} \mathrm{Y}^{+}$cannot be overlooked, and may indeed be the predominant path. Such a path is consistent with our explanation of the acid catalysis portrayed in section $b$. of the

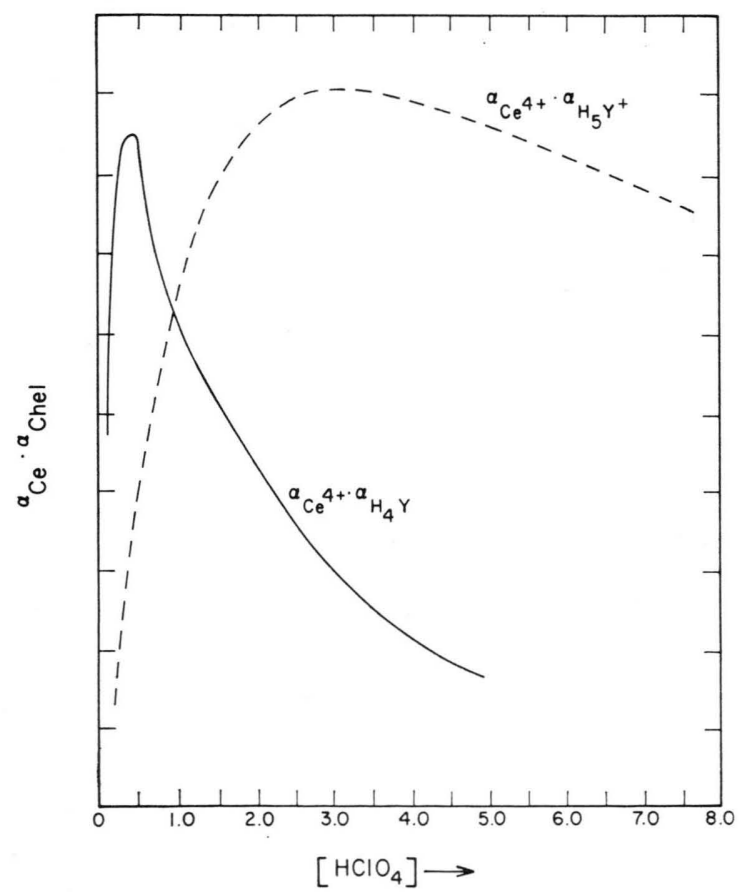

Fig. 3. Simulated reaction rates as a function of acid concentration. 


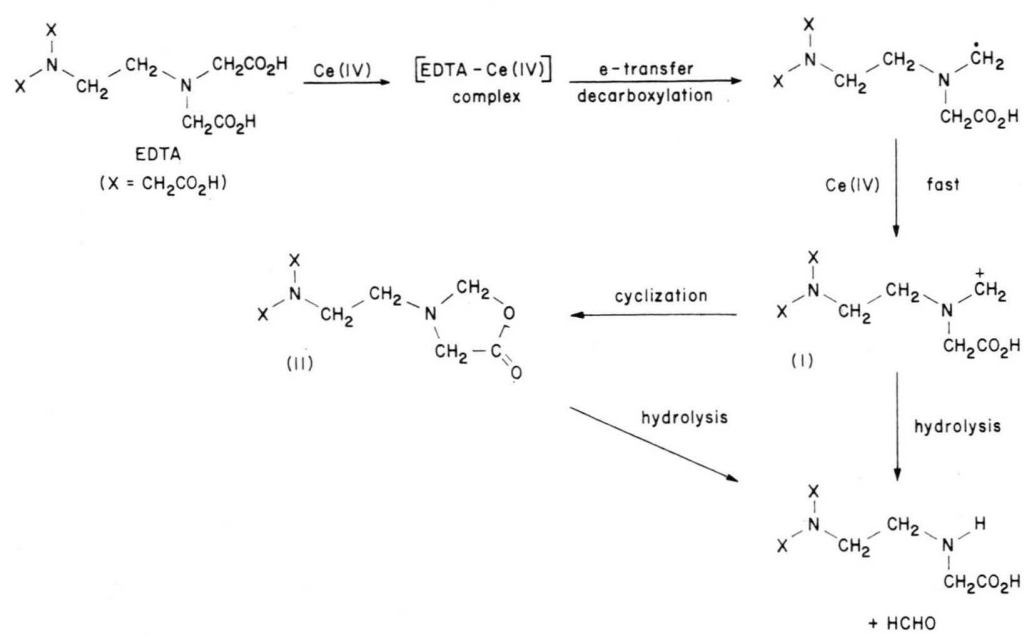

discussion. A third reaction path involving $\mathrm{Ce}(\mathrm{OH})^{3+}$ and $\mathrm{H}_{5} \mathrm{Y}^{+}$exhibits a behavior similar to the $\mathrm{Ce}^{4+-}-\mathrm{H}_{4} \mathrm{Y}$ path, with a maximum at $0.42 \mathrm{M} \mathrm{H}^{+}$. It is quite possible that the reduction of $\mathrm{Ce}(\mathrm{IV})$ by EDTA takes place via the three mentioned reaction paths simultaneously and that the observed rate is best expressed by equation (8),

$$
\begin{gathered}
\text { Rate }=a\left(\alpha_{\mathrm{Ce}^{4+}} \cdot \alpha_{\mathrm{H}_{4} \mathrm{Y}}\right)+\mathrm{b}\left(\alpha_{\mathrm{Ce}^{4+}}+\alpha_{\mathrm{H}_{5} \mathrm{Y}^{+}}\right)+ \\
\mathrm{c}\left(\alpha_{\mathrm{Ce}(\mathrm{OH})^{3+}} \cdot \alpha_{\mathrm{H}_{5} \mathrm{Y}^{+}}\right)
\end{gathered}
$$

where $\mathrm{a}, \mathrm{b}$ and $\mathrm{c}$ are parameters whose magnitudes

1 G. Anderegg and F. Wenk, Helv. Chim. Acta 54, 216 [1971].

2 A. S. Carson, P. G. Laye, and P. N. Smith, J. Chem. Soc., A, 1968, 1384.

3 G. Schwarzenbach, R. Gut, and G. Anderegg, Helv. Chim. Acta 37, 937 [1954].

${ }^{4}$ P. N. Palei and N. I. Udaltsova, Zhur. analyt. Khim. 15, 668 [1960].

5 D. Lambert and M. Jones, J. Amer. Chem. Soc. 88, 4616 [1966].

${ }^{6}$ R. Sanehi, R. M. Mehrotra, and S. P. Mushran, Z. Naturforsch. 28b, 483 [1973].

7 S. B. Hanna, S. Al-Hashimi, W. H. WebB, and W. R. Carroll, Z. Analyt. Chem. 246, 231 [1969].

8 S. B. Hanna, R. K. Hessley, W. H. Webb, and W. R. CARROLL, ibid. 255, 83 [1971].

${ }^{9}$ S. B. Hanna and R. K. Hessley, Inorg. Nucl. Chem. Letters 7, 83 [1971].

10 S. B. Hanna, R. K. Hessley, W. R. Carroll, and W. H. WeBB, Talanta 19, 1097 [1972].

11 J. Hardwick and E. Robertson, Canad. J. Chem. 29, 828 [1951].

${ }^{12}$ K. G. Everetr and D. A. Skoog, Analytic. Chem. 43, $1541[1971]$.

${ }^{13}$ F. R. Duke and F. R. Parchen, J. Amer. Chem. Soc. 78, 1540 [1956].

14 J. Hardwick and E. Robertson, Canad. J. Chem. 29, 818 [1951].

15 R. C. Spooner, J. Amer. Chem. Soc. 67, 167 [1945]. determine the contribution of each term to the overall reaction rate.

Finally we wish to propose the reaction sequence shown in Chart 2, which is to be considered mainly as a guideline for future studies. Possibly, the intermediate charged Schiff's base (I) cyclizes to the corresponding lactone(II), which accounts for only $4 \mathrm{Ce}(\mathrm{IV})$ reacting initially with the hydrolysis of (II) occurring afterward to give formaldehyde. Work with simpler amino acids is underway to test the proposed mechanism.

16 S. B. Hanna, L. M. Nicholson, and R. K. Hessley, Z. Analyt. Chem. 258, 126 [1972].

17 P. S. Sankhla and R. N. Mehrotra, J. Inorg. Nucl. Chem. 34, 3781 [1972].

18 L. Johansson, Coord. Chem. Rev. 12, 241 [1974].

$19 \mathrm{E}$. Chaffee and J. O. Edwards, in Inorganic Reaction Mechanisms - Progress in Inorganic Chemistry, Vol. 13, J. O. Edwards, Ed., Interscience Publishers, New York 1970.

20 G. Anderegg, Helv. Chim. Acta 46, 1833 [1963].

${ }^{21}$ R. F. Bogucki and A. E. Marteli, J. Amer. Chem. Soc. 80, 4170 [1958].

$22 \mathrm{~W}$. H. Richardson, in Oxidation in Organic Chemistry, Part I, Chapter 5, K. G. WIBERG, Ed., Academic Press, New York 1965.

23 N. I. Petschurowa, L. I. Martynenko, V. I. Spitzin, and E. A. Malinina, Z. Anorg. Allgem. Chem. 380, 202 [1971].

24 M. A. Paul, J. Amer. Chem. Soc. 76, 3236 [1954]; C. Perrin and F. Westhermer, ibid. 85, 2773 [1963].

25 U. D. Gomwalk and A. McAuley, J. Chem. Soc., A, 1968, 2948; A. McAuley, Coord. Chem. Rev. 5, 245 [1970].

${ }^{26}$ T. R. Bhat and R. Radhamma, Indian J. Chem. 3, 151 [1965].

27 L. J. Heidt and M. E. Smith, J. Amer. Chem. Soc. 70, 2476 [1948].

28 G. AnderegG, Helv. Chim. Acta 50, 3236 [1967]. 